\title{
UTILIZAÇÃO DAS ENZIMAS PEROXIDASES DO NABO NO CONTROLE DO ESCURECIMENTO ENZIMÁTICO EM MAÇÃS MINIMAMENTE PROCESSADAS
}

\author{
E. S. HARTWIG ${ }^{1}$, D. NOGUEIRA ${ }^{1}$; C. R. B. MENDONÇA ${ }^{1}$; J.D.F. da SILVA ${ }^{2}$; M. A. M. ALVES ${ }^{2}$; \\ C. D. BORGES ${ }^{1}$ \\ ${ }^{1}$ Universidade Federal de Pelotas, Centro de Ciências Químicas Farmacêuticas e de Alimentos \\ ${ }^{2}$ Instituto Federal de Alagoas, Campus Satuba \\ E-mail para contato: carlaufpel@hotmail.com/caroldellin@hotmail.com/mama_aguia@yahoo.com.br
}

\begin{abstract}
RESUMO - Objetivou-se avaliar a redução do escurecimento enzimático de maçãs minimamente processadas (MP) pela utilização de extrato de nabo e goma xantana. As maçãs foram minimamente processadas, seguindo aos distintos tratamentos: A - Controle; $\mathrm{B}$ - extrato de nabo; $\mathrm{C}$ - extrato de nabo e $\mathrm{CaCl}_{2}(1,0 \% \mathrm{p} / \mathrm{v}) ; \mathrm{D}-$ xantana $(0,25 \% \mathrm{p} / \mathrm{v})$, $\mathrm{CaCl}_{2}(1,0 \% \mathrm{p} / \mathrm{v})$ e glicerol $(1,0 \% \mathrm{v} / \mathrm{v}) ; \mathrm{E}$ - extrato de nabo; xantana $(0,25 \% \mathrm{p} / \mathrm{v}), \mathrm{CaCl}_{2}$ $(1,0 \% \mathrm{p} / \mathrm{v})$ e glicerol $(1,0 \% \mathrm{v} / \mathrm{v})$. Após os tratamentos, as maçãs foram secas, embaladas e armazenadas a $4{ }^{\circ} \mathrm{C}$ por 13 dias. Determinou-se a atividade das enzimas polifenoloxidase e peroxidase por espectrofotometria, e a cor utilizando-se colorímetro. Os dados mostraram que o extrato de nabo é eficiente para reduzir o escurecimento de maçãs MP. Observou-se um aumento considerável de atividade da enzima peroxidase nas maçãs tratadas com esse extrato, indicando que esse efeito seja o responsável pela redução do escurecimento nesta fruta. Entretanto, houve aumento da atividade da enzima polifenoloxidase durante o armazenamento em todos os tratamentos. Não se observou vantagem da associação do extrato de nabo com goma xantana ou com cloreto de cálcio.
\end{abstract}

\section{INTRODUÇÃO}

Maçãs minimamente processadas têm sido produzidas para serem comercializadas isoladamente ou em conjunto com outras frutas, além de serem utilizadas no preparo de tortas ou saladas. Entretanto, devido ao corte reações enzimáticas de escurecimento e a maior taxa de evaporação da água comprometem a aparência do produto.

O escurecimento enzimático é devido à reação oxidativa da polifenoloxidase sobre os compostos fenólicos, que geram a formação de $o$-quinonas, e que ao se polimerizarem formam pigmentos escuros denominados melanina (Lee, 1999).

Diversos produtos sintéticos podem controlar o escurecimento enzimático. Entretanto, devido ao aumento da demanda por produtos naturais em relação a estes, além da preocupação com a redução dos custos de produção, extratos de vegetais podem ser uma alternativa para inibir o escurecimento enzimático. 


\section{9 a 22 de outubro de 2014 \\ Florianópolis/SC}

O nabo (Brassica rapa L.), que pertence à família Cruciferae ou Brassicaceae, representa um dos vegetais cultivados mais antigos e vem sendo utilizado na alimentação humana desde os tempos pré-históricos (Saeed et al., 2012). É fonte de fibras, sais minerais e cálcio (Gondim, 2010), apresenta alto teor de vitamina $\mathrm{C}$ e antioxidantes que podem ajudar a limitar a formação de radicais livres e as reações oxidativas destrutivas (Saeed et al., 2012). Além disto, apresenta alta concentração da enzima peroxidase (Fatibello-Filho; Vieira, 2002). Esta por sua vez tem sido utilizada na descoloração de contaminantes de estrutura aromática e descoloração de corantes industriais e têxteis (Selvam; Swaminathan; Chae, 2003; Silva et al., 2012). Assim, o extrato de nabo pode ser uma opção natural para reduzir o escurecimento enzimático ocasionado pela polifenoloxidase nas maçãs minimamente processadas. Como veículo destes extratos podem-se utilizar os revestimentos comestíveis. Freitas et al. (2013), demonstrou a potencialidade da goma xantana como revestimento comestível de maçã minimamente processada.

Assim, objetivou-se avaliar a redução do escurecimento enzimático de maçãs minimamente processadas pela utilização de extrato de nabo e goma xantana.

\section{MATERIAL E MÉTODOS}

\subsection{Material}

Foram utilizadas amostras de maçã Fuji e nabo, adquiridas no comercio local de Pelotas/RS.

\subsection{Métodos}

Preparação do extrato de nabo: O nabo foi lavado e sanitizado com solução de hipoclorito de sódio $200 \mathrm{ppm}$, por 15 minutos. Após, foi descascado e a polpa triturada utilizando um multiprocessador de alimentos (Philips Walita). O extrato foi filtrado e adicionado de água na proporção 1:1.

Preparo da solução de goma xantana: A goma xantana (Shandong Fufeng Fermentation Co Ltda) foi preparada por dissolução lenta em água destilada $(0,25 \% \mathrm{~m} / \mathrm{v})$, a temperatura ambiente, sob agitação constante até completa dissolução (aproximadamente $2 \mathrm{~h}$ ), seguindo ao aquecimento por 20 minutos a $60^{\circ} \mathrm{C}$.

Processamento mínimo da maçã: As frutas foram lavadas e sanitizadas em solução de hipoclorito de sódio 200 ppm, por 15 minutos, para após serem descascadas e cortadas na metade, sendo estas metades ainda cortada em quatro pedaços.

Após, seguiram-se os distintos tratamentos: A - Controle (maçã sem revestimento); $\mathbf{B}$ - extrato de nabo; $\mathbf{C}$ - extrato de nabo e $\mathrm{CaCl}_{2}(1,0 \% \mathrm{p} / \mathrm{v}) ; \mathbf{D}-$ xantana $(0,25 \% \mathrm{p} / \mathrm{v}), \mathrm{CaCl}_{2}(1,0 \% \mathrm{p} / \mathrm{v})$ e glicerol (1,0 \% v/v); E - extrato de nabo; xantana $(0,25 \% \mathrm{p} / \mathrm{v}), \mathrm{CaCl}_{2}(1,0 \% \mathrm{p} / \mathrm{v})$ e glicerol $(1,0 \%$ $\mathrm{v} / \mathrm{v})$. Nos tratamentos de A a D, os pedaços de maçã foram imersos por 2 minutos nas respectivas soluções e secos sob ventilação em telas de nylon, por aproximadamente 4 h. Já no tratamento E, o recobrimento foi feito em duas etapas: primeiramente as frutas foram imersas no extrato de nabo por 


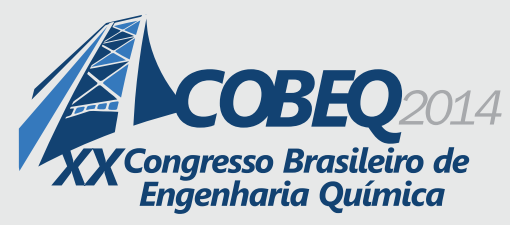

\section{9 a 22 de outubro de 2014 \\ Florianópolis/SC}

2 minutos e secas, e após foram imersas em solução de goma xantana por 2 minutos e novamente secas. Após os tratamentos, as maçãs foram embaladas em bandejas de poliestireno revestidas de policloreto de vinila, padronizando sete pedaços por embalagem. $\mathrm{O}$ armazenamento foi realizado a 4 $\pm 1{ }^{\circ} \mathrm{C}, 80 \%$ de umidade relativa, durante 13 dias.

Atividade enzimática: Para a extração das enzimas $1 \mathrm{~g}$ do tecido congelado foi homogeneizado com $10 \mathrm{~mL}$ de tampão fosfato $0,05 \mathrm{M}, \mathrm{pH} 7$, contendo $1 \%$ de polivinilpirrolidona e imediatamente filtrado. O homogenato obtido foi centrifugado por $15 \mathrm{~min}$ a $7.000 \mathrm{~g}$ e temperatura de $3{ }^{\circ} \mathrm{C}$ (Matsuno; Uritani, 1972). O sobrenadante resultante foi utilizado para a determinação da atividade enzimática das enzimas polifenoloxidase e peroxidase. Polifenoloxidase: uma alíquota de $1 \mathrm{~mL}$ de extrato enzimático foi adicionado a 3,6 mL de tampão fosfato $0,05 \mathrm{M}, \mathrm{pH} 6$ e $0,1 \mathrm{~mL}$ de pirocatecol 0,1 M. A solução obtida foi incubada durante $30 \mathrm{~min}$ a $30{ }^{\circ} \mathrm{C}$, e imediatamente resfriado em banho de gelo e realizada a leitura em espectrofotômetro (Bel) no comprimento de onda de $395 \mathrm{~nm}$. A atividade enzimática da polifenoloxidase foi expressa em unidade (atividade enzimática capaz de alterar 0,001 de absorbância a $395 \mathrm{~nm}$ ) por grama de polpa fresca por minuto (UAE.g ${ }^{-1} \cdot \mathrm{min}^{-1}$ ) (Campos; Silveira, 2003). Peroxidase: uma alíquota de $3 \mathrm{~mL}$ de extrato enzimático foi pipetada sobre uma solução contendo $5 \mathrm{~mL}$ de tampão fosfato citrato $0,02 \mathrm{M}, \mathrm{pH} 5,0,5 \mathrm{~mL}$ de peróxido de hidrogênio $30 \%$ e 0,5 $\mathrm{mL}$ de guaiacol. A solução foi incubada a $30{ }^{\circ} \mathrm{C}$ por $5 \mathrm{~min}$, e imediatamente resfriado em banho de gelo e realizada a leitura em espectrofotômetro no comprimento de onda de $470 \mathrm{~nm}$. A atividade da enzima peroxidase foi expressa em unidade (atividade enzimática capaz de alterar 0,001 de absorbância a $470 \mathrm{~nm}$ ) por grama de polpa fresca por minuto (UAE.g ${ }^{-1} \cdot \mathrm{min}^{-1}$ ) (Matsuno; Uritani, 1972).

Cor: Na análise de cor foram utilizados quatro pedaços de maçã, realizado oito leituras em cada período de análise, ou seja, duas leituras em cada pedaço. A cor foi determinada utilizando-se um colorímetro Minolta CR 400. Os valores $\mathrm{a}^{*}, \mathrm{~b}^{*}$ e $\mathrm{L}^{*}$ foram utilizados para calcular o Índice de Escurecimento (IE) de acordo com Palou et al. (1999), segundo a Equação 1, sendo o valor de X, nessa Equação, determinado por meio da Equação 2.

$$
\begin{aligned}
& I E=\frac{[100(X-0,31)]}{0,172} \\
& X=\frac{\left(a^{*}+1,75 L\right)}{\left(5,645+a^{*}-3,02 b^{*}\right)}
\end{aligned}
$$

Avaliação Estatística: Os resultados obtidos foram submetidos à análise de variância e a comparação de médias entre os tratamentos foi realizada pelo Teste de Tukey e Teste $t$ com nível de significância de $5 \%$, utilizando-se o programa Statistix 10. Para a descrição das variáveis em função dos períodos de armazenamento, foram realizadas análises de regressão polinomial.

\section{RESULTADOS E DISCUSSÃO}

Houve aumento da atividade da enzima polifenoloxidase durante o armazenamento em todos os tratamentos (Figura 1A). Já em relação à atividade da enzima peroxidase (Figura 1B), nos tratamentos adicionados de extrato de nabo, a atividade foi consideravelmente superior aos não adicionados. Entretanto, ao longo do armazenamento, houve tendência de redução da atividade desta enzima. 
Segundo Valderrama, Ayala e Vázquez-Duhalt (2002), as peroxidases são instáveis e susceptíveis à inativação na presença de peróxido de hidrogênio. Esta auto-inativação oxidativa parece ocorrer por diferentes vias catalíticas, incluindo a heme destruição e oxidação de aminoácidos essenciais.
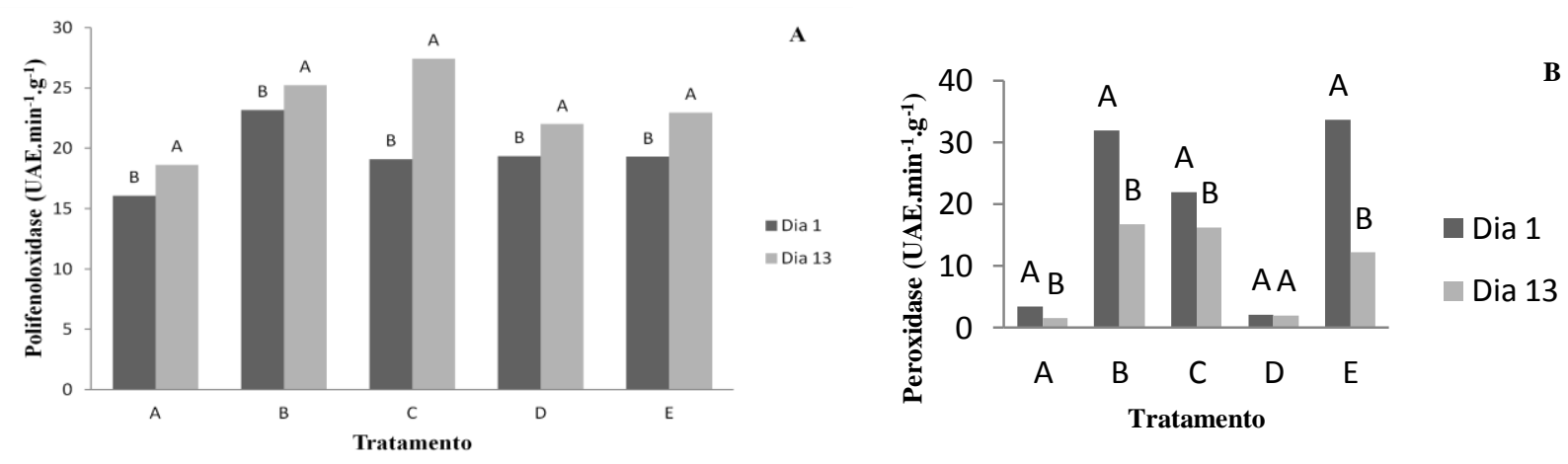

Figura 1 - Atividade das enzimas polifenoloxidase (UAE.min- ${ }^{1} \cdot \mathrm{g}_{-}{ }^{1}$ ) (A) e peroxidase (UAE.min- ${ }^{1} \cdot \mathrm{g}_{-}{ }^{1}$ ) (B) em maçãs minimamente processadas adicionadas de extrato de nabo e goma xantana, no $1^{\circ}$ e $13^{\circ}$ dia de armazenamento a $4 \pm 1{ }^{\circ} \mathrm{C}$.

Conforme a Tabela 1, não houve aumento significativo do índice de escurecimento das maçãs minimamente processadas durante o armazenamento nos tratamentos $\mathrm{B}$ e $\mathrm{C}$, ambos adicionados de extrato de nabo. Nos demais tratamentos, pode-se observar aumento significativo deste índice durante o armazenamento, inclusive no tratamento $\mathrm{E}$ (extrato de nabo e goma xantana), ainda que em menor proporção que nos demais.

Tabela 1 - Índice de escurecimento de maçãs minimamente processadas adicionadas de extrato de nabo e goma xantana, armazenadas a $4 \pm 1^{\circ} \mathrm{C}$ por 13 dias

\begin{tabular}{|c|c|c|c|c|c|c|}
\hline \multirow{2}{*}{ Tratamento- } & \multicolumn{5}{|c|}{ Dias de armazenamento } & \multirow{2}{*}{ Regressão Polinomial } \\
\hline & 1 & 3 & 6 & 9 & 13 & \\
\hline A & $33,73 \pm 4,09 \mathrm{~A}$ & $33,35 \pm 3,44 \mathrm{~A}$ & $35,66 \pm 1,63 \mathrm{~A}$ & $34,94 \pm 3,00 \mathrm{AB}$ & $44,09 \pm 4,49 \mathrm{~A}$ & $\begin{array}{c}y=0,115 x^{2}-0,8188 x+34,785 \\
R^{2}=0,9193\end{array}$ \\
\hline B & $28,59 \pm 2,95 \mathrm{AB}$ & $26,25 \pm 1,89 \mathrm{~B}$ & $28,58 \pm 1,79 \mathrm{~B}$ & $29,57 \pm 2,71 \mathrm{BC}$ & $29,28 \pm 2,62 \mathrm{C}$ & $(\mathrm{ns}) \mathrm{y}($ média $)=28,45$ \\
\hline $\mathrm{C}$ & $24,22 \pm 4,37 \mathrm{~B}$ & $28,61 \pm 3,62 \mathrm{AB}$ & $27,79 \pm 3,20 \mathrm{~B}$ & $28,01 \pm 4,37 \mathrm{C}$ & $29,86 \pm 4,55 \mathrm{C}$ & (ns) y (média) = 27,69 \\
\hline $\mathrm{D}$ & $31,40 \pm 3,25 \mathrm{~A}$ & $32,69 \pm 1,42 \mathrm{~A}$ & $37,25 \pm 3,46 \mathrm{~A}$ & $36,32 \pm 3,6 \mathrm{~A}$ & $37,36 \pm 2,66 \mathrm{~B}$ & $\begin{array}{c}y=-0,0651 x^{2}+1,4077 x+29,846 \\
R^{2}=0,8936\end{array}$ \\
\hline $\mathrm{E}$ & $25,66 \pm 3,04 \mathrm{~B}$ & $26,32 \pm 3,86 \mathrm{~B}$ & $29,83 \pm 1,91 \mathrm{~B}$ & $31,26 \pm 3,37 \mathrm{ABC}$ & $32,78 \pm 3,07 \mathrm{BC}$ & $\begin{array}{c}y=-0,0284 x^{2}+1,029 x+24,265 \\
R^{2}=0,9756\end{array}$ \\
\hline
\end{tabular}

Médias seguidas de mesma letra maiúscula na coluna não diferem entre si, pelo Teste de Tukey $(\mathrm{p}<0,05)$. Tratamentos: A - Controle (maçã sem revestimento); $\mathbf{B}$ - extrato de nabo; $\mathbf{C}$ - extrato de nabo e $\mathrm{CaCl}_{2}(1,0 \% \mathrm{p} / \mathrm{v})$; $\mathbf{D}$ - xantana $(0,25 \% \mathrm{p} / \mathrm{v}), \mathrm{CaCl}_{2}(1,0 \% \mathrm{p} / \mathrm{v})$ e glicerol $(1,0 \% \mathrm{v} / \mathrm{v}) ; \mathbf{E}$ - extrato de nabo; xantana $(0,25 \% \mathrm{p} / \mathrm{v}), \mathrm{CaCl}_{2}$ $(1,0 \% \mathrm{p} / \mathrm{v})$, e glicerol $(1,0 \% \mathrm{v} / \mathrm{v})$.

As diferenças iniciais no índice de escurecimento ocorreram em função da influência do revestimento durante a secagem do revestimento (Tabela 1), possivelmente devido à atividade da enzima peroxidase. Assim, aqueles adicionados de extrato de nabo, inclusive o tratamento E, foram os 
que apresentaram menores índices de escurecimento, tanto no início do armazenamento, como no término.

Silva et al. (2012) descreveram a reação de degradação de compostos fenólicos, conforme reações abaixo:

$$
\begin{gathered}
\text { Peroxidase }+\mathrm{H}_{2} \mathrm{O}_{2} \rightarrow \text { Composto I }+\mathrm{H}_{2} \mathrm{O} \\
\text { Composto I }+\mathrm{AH}_{2} \rightarrow \text { Composto II }+\mathrm{A} \bullet \\
\text { Composto II }+\mathrm{AH}_{2} \rightarrow \text { Peroxidase }+\mathrm{AH} \bullet+\mathrm{H}_{2} \mathrm{O}
\end{gathered}
$$

No primeiro estágio do processo catalítico, ocorre a reação do sítio ativo com o peróxido de hidrogênio. O peróxido de hidrogênio é reduzido produzindo água e o composto I, uma forma intermediária reativa que apresenta um estado de oxidação mais alto em comparação com a enzima nativa. No segundo estágio, o composto I oxida uma molécula de substrato $\left(\mathrm{AH}_{2}\right)$, neste caso o corante aromático, gerando um substrato radicalar e o composto II. Finalmente, o composto II é reduzido por uma segunda molécula de substrato, fazendo com que a enzima retorne a sua forma inicial. Os radicais livres formados durante o ciclo $(\mathrm{AH} \cdot)$ difundem-se do sítio ativo da enzima para o meio da solução. Estes radicais livres são reativos e tendem a iniciar uma reação espontânea, em cadeia, em que as moléculas aromáticas são ligadas formando um produto poliaromático com solubilidade reduzida o que explicaria a precipitação do corante pela ação de peroxidases.

Possivelmente, no tratamento E, a goma xantana tenha propiciado menor permeabilidade ao oxigênio fazendo com que a atividade da peroxidase fosse parcialmente inibida, quando comparada ao tratamento em que foi utilizado somente o extrato (B) ou extrato e cloreto de cálcio (C). De acordo com Krochta e Mulder-Johnston (1997), os revestimentos comestíveis promovem a formação de barreiras semi-permeáveis ao oxigênio. Além disto, estudos preliminares (resultados não mostrados) revelaram que o efeito da inibição do escurecimento enzimático pelo nabo em embalagens de poliestireno revestidas com policloreto de vinila foi superior a embalagem de polietileno tereftalato, visto que a primeira apresenta maior permeabilidade ao oxigênio, por isso, sendo este tipo de embalagem adotado para a realização do experimento.

\section{CONCLUSÃO}

Os dados mostraram que o extrato de nabo é eficiente para reduzir o escurecimento de maçãs MP. Observou-se um aumento considerável de atividade da enzima peroxidase nas maçãs tratadas com esse extrato, indicando que esse efeito seja o responsável pela redução do escurecimento nesta fruta. Entretanto, houve aumento da atividade da enzima polifenoloxidase durante o armazenamento em todos os tratamentos. Não se observou vantagem da associação do extrato de nabo com goma xantana ou com cloreto de cálcio. 


\section{REFERÊNCIAS}

CAMPOS, A. D.; SILVEIRA, E. M. da L. Comunicado Técnico: Metodologia para determinação da peroxidase e da polifenol oxidase em plantas. Pelotas: Embrapa Clima Temperado, 2003.

FATIBELLO-FILHO, O.; VIEIRA, I. C. Uso analítico de tecidos e de extratos brutos vegetais como fonte enzimática. Quím. Nova, v.25, n.3, p.455-464, 2002.

FREITAS, I. R.; CORTEZ-VEJA, W. R.; PIZATO, S.; PRENTICE-HERNÁNDEZ, C.; BORGES, C. D. Xanthan gum as a carrier of preservative agents and calcium chloride applied on fresh-cut apple. $J$. Food Saf., v. 33, n. 3, p. 229-238, 2013.

GONDIM, A. Catálogo brasileiro de hortaliças. Brasília: Embrapa, 2010. 59p.

KROCHTA, J. M.; MULDER-JOHNSTON, C. Edible and biodegradable polymer films: challenges and opportunities. Food Technol., v. 51, n. 2, p. 61-77, 1997.

LEE, C. Y. Encyclopedia of food science and technology. 2. ed. New York: Wiley, 1999.

MATSUNO, H.; URITANI, I. Physiological behavior of peroxidase enzymes in sweet potato root tissue injured by cutting or black root. Plant Cell Phys., v. 13, n. 6, p. 1091-1101, 1972.

PALOU, E.; LÓPEZ-MALO, A.; BARBOSA-CÁNOVAS, G. V.; WELTI-CHANES, J.; SWANSON, B. G. Polyphenoloxidase activity and color of blanched and high hydrostatic pressure treated banana puree. J. Food Sci., v. 64, n. 1, p.42-45, 1999.

SAEED, M. K.; ANJUM, S.; AHMAD, I.; NISA, A.; ALI, S.; ZIA, A.; ALI, S. Nutritional facts and free radical scavenging activity of turnip (Brassica rapa) from Pakistan. World App. Sci. J., v.19, n.3, p.370-375, 2012.

SELVAM, K.; SWAMINATHAN, K.; CHAE, K. S. Decolorization of azo dye and a dye industry effluent by a white rot fungus Thelephora sp. Biores. Technol., v.88, n.2, p. 115-119, 2003.

SILVA, M. C.; CORRÊA, A. D.; TORRES, J. A.; AMORIM, M. T. S. P. Descoloração de corantes industriais e efluentes têxteis simulados por peroxidase de nabo (Brassica campestre). Quím. Nova, v. 35, n. 5, p. 889-895, 2012.

STATISTIX 10. Disponível em: http://www.statistix.com/free-trial/. Acesso em: outubro, 2013.

VALDERRAMA, B.; AYALA, M.; VÁZQUEZ-DUHALT, R. 2002. Suicide inactivation of peroxidases and the challenge of engineering more robust enzymes. Chem. Biol., v. 9, n. 5, p. 555565, 2002. 